\title{
On Stress State Measurements of Rock Massifs with Underground Facilities Convertible into Defense Shelters
}

\author{
Petr KUBEČEK ${ }^{1}$, Vaclav POSPICHAL ${ }^{1}$, Małgorzata GAWLIK-KOBYLIŃSKA ${ }^{2}$, Jiří $^{\prime}$ \\ ŠTOLLER ${ }^{3}$, Frantisek PAULUS ${ }^{4}$
}

${ }^{1}$ Czech Technical University in Prague, Faculty of Civil Engineering, Thákurova 7/2077, Prague 6 - Dejvice, 166 29, Czech Republic

${ }^{2}$ War Studies University, Management and Command Faculty, gen. Antoniego Chruściela "Montera” Street 103, Warszawa, 00-910, Poland

${ }^{3}$ University of Defence, Faculty of Military Technology, Kounicova 65, 66210 Brno, Czech Republic

${ }^{4}$ Ministry of interior - General Directorate of Fire Rescue Service of the Czech Republic, Population Protection Institute, Na Lužci 204, 53341 Lázně Bohdaneč, Czech Republic

E-mail: alexandr.kravcov@fsv.cvut.cz

\begin{abstract}
When considering the scale of the rock massif to solve a specific rock problem, it is necessary to consider the structure of the massif within this scale (volume). If the structure is homogeneous within the scale of the massif, the solution can use existing ideas about the properties of rocks in the massif and the scale effect. A homogeneous massif can be composed of micro-heterogeneous "mother" elements. In this case, consideration of rock strength characteristics is associated with statistical characteristics considered in laboratory tests of rock properties. This mathematical apparatus can be important during the selection of rock massif that could be appropriative enough for location of fallout shelters for protection of civilian population against the effects of Nuclear Weapons.
\end{abstract}

KEY WORDS: rock properties, mathematical models, rock mass, rheological properties

\section{Introduction}

A heterogeneous massif within the volume required when considering a specific problem may have different categories of structural elements related to the size of the structural cleavages. In principle, the presence of first, second, etc. orders fracturing within the massif makes it necessary to distinguish the massifs by the value of the maximum order of the fracturing located in it $[1,2]$. Thus, in this case, the scale of the massif, i.e., its volume needed to consider the problem to be solved, will be characterized by a certain order.

\section{The Mathematical Formulation of the Problem}

We presented a diagram explaining the determination of the order of the rock mass depending on the scale of the mass and the order of fracturing.

For the entire second-order element as a whole, according to the classical theory of elasticity, the volume potential energy from the impact of the load $\mathrm{P}$ is defined as $\mathrm{n}$

$$
A=\frac{\sigma \varepsilon}{2}=\frac{1}{2 n} \frac{\sum_{1}^{n} P_{i}\left(n a-\sum_{1}^{n} a_{i}\right)}{a^{3}} .
$$

Then, on the volume of the second-order element $\mathrm{V}=$ na3, the work of external forces will be

$$
W_{I I}=\frac{1}{2 n} \sum_{1}^{n} P_{i}\left(n a-\sum_{1}^{n} a_{i}\right)
$$

The average energy under the effect of the force distributed on the elements of the first order is defined as

\footnotetext{
${ }^{1}$ Corresponding author.

E-mail address: alexandr.kravcov@fsv.cvut.cz
} 


$$
A_{c p}=\frac{\sum_{1}^{n} A_{i}}{n}=\frac{1}{2 n} \frac{\sum_{1}^{n} P_{i}\left(a-a_{i}\right)}{a^{3}} .
$$

The work of external forces on the i-th element of the first order

$$
W_{1}=P_{1}\left(a-a_{1}\right)
$$

Therefore, the actual work of external forces on the elastic displacements of a second-order system consisting of first-order elements will be

$$
W_{I I}^{\prime}=\frac{1}{2} \sum_{1}^{n}\left[P_{i}\left(a-a_{i}\right)\right] .
$$

According to (2), we have that

$$
W_{I I}^{\prime}=A_{c p} V .
$$

As a result, we obtain

$$
W_{I I} \neq W_{I I}^{\prime}
$$

Thus, the potential energy of a massif of individual structural elements is the sum of the average values, and not the total potential energy of the individual elements.

The discrepancy between the actual work of the second-order massif and the work calculated for the massif as a whole will be the less the smaller is the coefficient of variation of the elastic characteristics, that is, when the difference is small

$$
\Delta A=A_{c p}-A_{i}
$$

In particular, if the coefficient of variation of the elastic and deformation characteristics of first-order elements is minimal (equal to zero), then according to (2) and (5)

$$
W_{I I}=W_{I I}^{\prime}=\frac{n}{2} P\left(a-a_{i}\right)
$$

The more heterogeneous the structural characteristic of the massif, the greater is the importance of considering the variation in the properties of the constituent elements of the massif. A massif composed of homogeneous elements can be classified as a homogeneous one.

Experience of locating shelters in mine shafts shows that conditions for safety of hiding persons have to be inspected for stability in a relatively large number of shafts in each mine.

The analysis of factors influencing the tension of rocks around shafts shows that, with respect to designing of shelters with specified parameters of particle velocity, the most effective method of assessment of shaft stability seems to be calculation of change in depth of the limit position of rock outcrops in dependence on strength characteristics of the rocks.

The limit depth $\left(H_{\text {lim, }}, \mathrm{m}\right)$ at which the stability of rocks at the shaft perimeter is retained can be determined by solving a limit equilibrium equation.

$$
H_{\lim }=\frac{R_{c}-\sigma_{\text {static }}}{10^{=4} \gamma\left(K_{p}+\xi K_{q}\right)\left(\cos ^{2} \alpha-\xi \sin ^{2} \alpha\right)}
$$

where $R_{c}$ - design rock resistance to pressure or expansion, $\mathrm{kgs} / \mathrm{cm} 2$; 
$\sigma_{\text {static }}$ - equivalent static load due to seismic waves.

Load due to seismic waves

$$
\begin{aligned}
& \sigma_{\text {static }}=\left[\left(\rho C_{p}^{M} U_{c z}+\sigma_{\text {swstatic }}\right)\left(\cos ^{2} \alpha+\zeta \sin ^{2} \alpha\right)+\rho C_{p}^{M} U_{c x}\left(\sin ^{2} \alpha+\zeta \cos ^{2} \alpha\right)\right] K_{p}+ \\
& +\zeta\left(\rho C_{p}^{M} U_{c z}+\rho C_{p}^{M} U_{c x}+\sigma_{\text {sustatic }}\right) K_{q}, \mathrm{kgs} / \mathrm{cm}^{2}
\end{aligned}
$$

$\rho C_{p}^{M}$ - where acoustic resistance of rocks in the massif, $\mathrm{kgs} / \mathrm{cm}^{3}$, where $C_{p}^{M}$ - velocity of the shock wave propagation in the rocks massif;

$U_{c Z}, U_{c X}-$ vertical and horizontal components of particle velocity in $\mathrm{cm} / \mathrm{sec}$;

$\sigma_{\text {static }}$ - equivalent static load due to pressure wave (shock wave pressure), $\mathrm{kgs} / \mathrm{cm}^{2}$.

\section{Results and Discussion}

Method of the calculation effectiveness is achieved by solving the problem under conditions for various mines within the extent of change in the strength and elasticity properties of the rocks. A comprehensive calculation of change in the values of $H_{\text {lim }}$ is dependence on the rock strength is made with respect to the relationship between mechanical and acoustic properties and specific properties of the geological structure of the rock layer.

After summarising the results of experimental studies of acoustic and mechanical properties of rocks in samples and implementation of the obtained data in shaft conditions, we obtain the dependence between the breaking strength under pressure and the acoustic resistance of rocks in the massif, which can be used in comprehensive calculations of limit equilibrium.

Table 1.

Dependence between the breaking strength under pressure and the acoustic resistance of rocks

\begin{tabular}{|l|c|c|c|c|c|c|c|}
\hline Rock resistance to compression in massif & 50 & 100 & 200 & 400 & 800 & 1200 & 1600 \\
\hline Acoustic resistance of rocks & 0.2 & 0.4 & 0.6 & 0.8 & 1.0 & 1.2 & 1.4 \\
\hline
\end{tabular}

The mass density of rocks with a sufficient accuracy for this calculation can be accepted as a mean value of this parameter under the conditions of the studied mine.

The lateral pressure coefficient $\xi=f(v)$ does not depend on the strength and other properties of rocks, even though some categories of rocks do show a regular decrease in the Poisson's ratio $v$ with increasing rock strength. Rocks that have a tendency to relax tension are examined separately for lateral pressure effects. In connection with that, calculations are made separately for a number of coefficients $v$ and, $\xi$ including their range of variability.

For shafts with an incline up to $20^{\circ}$, the inclination angle $\alpha$ in the calculations is considered 0 as a consequence of the negligible effect of the inclination angle on the final calculation results.

As is well-known, the nature of effect of seismic waves of the rock massif depend on the geological structure of the area and, first and foremost, on the thickness of the covering layer of soft soils $h_{0}$. With an insignificant value of $h_{0}\left(h_{0} \leq h_{k}\right)$, the vertical and horizontal component of the particle velocity $\left(U_{c z}, U_{c x}\right)$ for the specified class of shelters is considered a stable value, independently of the depth of the mine excavation $\mathrm{H}$, and these components equal each other. For the case $h_{0}>h_{k}$, the value of $U_{c z}$ changes in dependence on the depth H. It turns out that the loading due to the seismic wave $\sigma_{\text {swstatic }}$ is also a variable quantity, dependent on the depth $\mathrm{H}$. With respect to the defined specificities of the effects of seismic waves, the calculation has to be performed in the following sequence. At first, the value $H_{\lim }$ is determined regardless of the load change due to the pressure wave $\sigma_{\text {swstatic }}$. In case $h_{0}>h_{k}$, the value of $U_{c z}$ is taken equal $U_{c X}$. After that thanks to $H_{\text {lim }}$ we can get the value of $\sigma_{\text {swstatic }}$ and $U_{c z}$ in depth $H=H_{\text {lim }}$.

Vertical and horizontal pressure from the shock wave we can get from

$$
\sigma_{c z}=\rho C_{p}^{M} U_{c z}, \mathrm{kgs} / \mathrm{cm}^{2}
$$


and

$$
\sigma_{\dot{c} x}=\rho C_{p}^{M} U_{c x}, \mathrm{kgs} / \mathrm{cm}^{2}
$$

The tension status of an undisrupted massif is considered to be hydrostatic pressure for all rock types when calculating tension due to static loading with rock pressure.

Examination of the temporal and linear characteristics of the waves reveals that, under mine shaft (chamber) conditions, tensions due to seismic waves are of a quasistatic nature. In some cases, the length of the wave () exceeds the shaft cross-section dimensions. It has been both theoretically and practically proven that with $\frac{\lambda}{B} \geq 4$ (B-shaft span) the dynamic tension coefficient is equal to the static one, or exceeds it by no more than $10 \%$. Besides, the quasistatic nature of the dynamic tension does not change the strength characteristics of rocks unlike static tension. In this case, the coefficient of dynamic strengthening of rocks is near 1.

The extreme complexity of a mechanical model of rock mass loading development, taking into account its various zones and orders, as well as the practical impossibility of directly assessing rock characteristics in these massifs, led to the fact that the mass loading process can be estimated by the degree of stress state of the rocks composing the rock mass.

It is no accident, therefore, that a great deal of experience has been accumulated at present in creating instruments and methods for assessing the stress state of rocks in massifs. Achievements in this area were summarized in sufficient detail in [3, 4] and there is no need to repeat them [10-14]. We restrict ourselves to providing examples of actual measurements of the stress state of rocks in the massif, indicating the inconsistency of the measured stress values with modern ideas about the causes of the formation of the stress field in the earth's crust, the direction of the main stresses and their magnitudes.

Along with the development and improvement methods and instruments for measurements at various points of the earth's crust, a large number of actual stress measurements were performed in a wide variety of rocks and in various mining and geological conditions at depths from the surface of up to $1000 \mathrm{~m}$ in mines, quarries, and foundations of hydraulic structures. The stress state of the so-called undisturbed massifs of rocks and in the unloading zones, near natural or artificial outcrops, was investigated.

One of a current hypothesis is standing that the source of stresses in the earth's crust are gravitational forces, i.e., the weight forces of the overlying rock strata. According to this hypothesis, the stress tensor at an arbitrarily chosen point of the earth's crust is oriented in a certain way in space, and the components of the stress tensor are a function of the depth of the considered point of the massif and the weight of the overlying rock mass.

When array is placed under stress, its volume decreases as mineral grains compress, rearrange their positions, or both. If the massive is saturated, this volumetric compression corresponds to a net outflow of pore water, and the media is consolidating. Consolidation strains can be large, causing displacement of serious magnitude within the rock mass. Consider only cases in which the applied stresses are of such magnitude or of such proportion as not to threaten shear failure of the array. The above description concerns the consolidation behavior of saturated soil; the consolidation behavior of unsaturated solid mass under compression loading is more complex, in that pore gasses (e.g. air) are compressible. In this case, compression of the soil may correspond to a net particle outflow of pore water, a approximately net outflow of pore gases, and a net compression of the pore gas. This more complex case of unsaturated solid array consolidation is not further considered.

As stress increments are added to the saturated array, the relative incompressibility of the pore water compared to the mineral skeleton leads to the octahedral stress increment being borne by the water alone. However, since the water cannot sustain shear stress, deviator stresses are borne by the mineral skeleton alone $[5,6]$. Consolidation is the slow process by which outflow of pore water due to the pore pressure gradient from inside the specimen or stressed volume to the outside causes a gradual decrease in pore water pressure and a corresponding transfer of stress from the water to the mineral skeleton.

As stress builds upon the mineral skeleton, the latter compresses due to the combined action of particle deformation and particle rearrangement, and the macroscopic volume of the specimen decreases. This definition of consolidation is sufficiently broad to apply to the three-dimensional as well as the one-dimensional case, the latter being the case routinely measured in the laboratory [7].

Along with this hypothesis, there is the so-called hypothesis of hydrostatic stress state, characterized by a spherical tensor. This view is justified by relaxation processes that occur in the earth's crust and lead to equalization of stresses.

Both hypotheses about the stress state of the rock mass are used in solving specific problems of mechanics. 
The initial calculation formulas, in accordance with the stated hypotheses, are in the first case

$$
\sigma_{1}=\gamma H, \sigma_{2}=\sigma_{3}=\frac{\mu}{1-\mu} \gamma H
$$

In the second one

$$
\sigma_{1}=\sigma_{2}=\sigma_{3}=\frac{\mu}{1-\mu} \gamma H
$$

Where $\sigma_{1}, \sigma_{2}, \sigma_{3}$, are the main stresses; $\mu$ is Poisson's ratio; $\gamma$ is volumetric weight of rocks; $H$ is the depth of the considered element of the rock.

Measurements of stresses at various points of the earth's crust, performed in recent years, reveal that the actual stress field is significantly different from the fields described by equations (11) and (12). What until recently was considered the rule was a rare exception. The actual stress field, as a rule, is described by an unequal component tensor: all three principal stresses are different, the orientation of the tensor in space is arbitrary and is determined not only by the depth of the point under consideration, but also by a number of other factors.

The first hypothesis is also untenable because if we accept it for estimating the stress field, then the surface values of stresses will be insignificant or completely absent. In fact, rocks, especially rock, located directly on the daylight surface, are already stressed, they have hidden internal stresses that can be called residual; the manifestations of them are well known. Manifestations of residual stresses in the outcrops are especially pronounced in the form of unloading cracks, and when breaking large blocks of lining stones in quarries, residual stresses are used to select the optimal direction of spallation of blocks.

The accumulated material on the study of stress fields by various methods (unloading methods, geological, geophysical, seismic, etc.) allows us to explain the nature of residual stresses [8]. Apparently, the main part of the residual stresses is due to the weight of the overlying strata that formed the stress field in remote geological periods. In relation to sedimentary rocks of a coal formation, these are periods of sedimentation, lithification, and subsequent changes, including metamorphism. The immersion of rock strata to a depth of 10-15 km caused a large elastic compression with the accumulation of significant reserves of elastic energy per unit volume of the massif.

Removing the initial loads (in whole or in part) causes a stepwise unloading of the rocks, which manifests itself in the form of a deformation of the outcrop contour movement. Such a deformation can be changed, and on the base of its magnitude, using the inverse calculation, the stresses acting at the measured point can be determined. This path is the basis of the currently widely used unloading method for determining stresses in a rock mass.

The stress state caused by gravitational forces is superimposed by the stress state caused by tectonic forces during certain geological periods. The addition of gravitational and tectonic stress fields caused a new field, changed the orientation of the stress components and their magnitudes. This circumstance is very significant and cannot be neglected when considering the stress state of the rock mass. It should also be remembered that individual sections and large regions are not at rest, but are subjected to raising or lowering as a result of directed efforts, which remove large massifs of rocks from the equilibrium state, causing redistribution and changes in the stress field during their loading.

Accumulated facts on rock unloading and measured stresses give reason to presumably judge the stress state of rock masses [9]. As already mentioned, none of the two existing hypotheses can be considered satisfactory, since they are not confirmed by experimental verification.

\section{Conclusions}

Based on the foregoing, it should be noted that at present there is a problem associated with the approximation of data on the properties of the rock mass obtained during field exploration and laboratory work, as applied to largescale objects, such as mine facility. In other words, today, to a greater extent, there are no qualitative coupling coefficients of different scale levels for predicting the stress-strain state of a rock mass. Calculation of change in depth of the limit position of rock outcrops in dependence on strength characteristics of the rocks appears like the mostly effective method of assessment of shaft stability.

Hypothesis of hydrostatic stress state and gravitational forces cannot be considered sufficient and satisfactory due to there are not confirmed by experimental verification. 


\section{Acknowledgements}

This research work was supported by the National Ministry of Education of Czech Republic (No. 027/0008465), authors also want to thanks to the Czech Technical University in Prague endowment for support in part of the advanced monitoring of the stability and the technical state of the geological structure of the heritage reservation of Prague.

\section{References}

1. Hilar, M., Pruška, J., Statistical Analysis of Input Parameters Impact on the Modelling of Underground Structures, Acta Polytechnica. 2008, 48(5), 3-8. ISSN 1210-2709.

2. Kravtsov, A.; Svoboda, P.; Pospíchal, V.; Zdebsky, J., Experimental Studies on Process of Transition of Explosion to Deflagration due to Methane Gas Explosion in Underground Structures, ICMT 2015 - International Conference on Military Technologies 2015. Rio de Janeiro: IEEE Institute of Electrical and Electronics Engineers Inc., 2015. pp. 125-133. ISBN 9788072319763.

3. Kravtsov, A.; Svoboda, P., Experimental Studies of the Blast Pressure due to an Explosion in the Tunnel, Proceedings from the Fourth International Symposium on Tunnel Safety and Security. Stockholm: Royal Institute of Technology, 2014. pp. 281-288. ISSN 0284-5172. ISBN 978-91-86319-44-1.

4. Harami, K.Y., Brady, B.T., A Methodology to Determine in Situ Rock Mass Failure, Internal report of Bureau of Mines, Denver, CO, USA, 1995

5. Jao, M., Wang, M.C., Behavior of soft ground tunnel under strip footing, Geotechnical Special Publication, (102), 2002

6. Vaníček, I., Jirásko, D., Vaníček, M., Pruška, J., Underground structure monitoring for quality control during operation - example for prague metro, Urban Planning Below the Ground Level: Architecture and Geotechnics. ISSMGE, 2018.

7. Kravcov, A., Franek O., Morozov, N., Kucewicz, M., Tomaszewski, M., Svoboda, P., Baranowski, P., Laser ultrasonic measurement of mechanical decay in limestone caused by freeze-thaw cycles, Acta Polytechnica, 2019, ISSN 1210-2709.

8. Kravcov, A.; Morozov, N.; Svoboda, P.; Pospíchal, V.; Zezulová, E., Quality assessment of bored pile foundations by a set of nondestructive testing methods, 2019 International Conference on Military Technologies (ICMT). IEEE (Institute of Electrical and Electronics Engineers), 2019. p. 87-91. ISBN 978-1-7281-4594-5.

9. Pruška, J., Kožoušek, A., Evaluation of the non-homogenous subsoil by LAS simulation, 12th International Conference Underground Construction Prague 2013. Praha: Česká tunelářská asociace ITA-AITES, 2013. ISBN 978-80-260-3868-9.

10. Hošková-Mayerová, Š.; Talhofer, V.; Hofmann, A.; et al. 2013. Mathematical Model Used in Decision-Making Process with Respect to the Reliability of Geodatabase, Advanced Dynamic Modeling of Economic and Social Systems, Book Series: Studies in Computational Intelligence, vol. 448, 143 p.

11. Hošková-Mayerová, Š.; Talhofer, V.; Hofmann, A.; et al. 2013. Spatial Database Quality and the Potential Uncertainty Sources, Advanced Dynamic Modeling of Economic and Social Systems, Book Series: Studies in Computational Intelligence, vol. 448, 127 p.

12. Cibulová, K. 2017. Instruments Used for Terrain Evaluation in the Army of the Czech Republic: Transport Means 2017. Kaunas: Kaunas University of Technology, 840-844. ISSN 1822-296X.

13. Cibulová, K. 2017. The Mobility during Crisis Situations. In: Structural and Mechanical Engineering for Security and Prevention ICSMESP 2017. Switzerland: Trans Tech Publications, 236-241. ISSN 1662-9809.

14. Cibulová, K. 2018. Comparative Measurement of Instruments Used for Evaluation of Terrain Trafficability. Transport Means 2018. Kaunas: Kaunas University of Technology, 1147-1150. ISSN 1822-296X. 